Association for Information Systems

AIS Electronic Library (AISeL)

Wirtschaftsinformatik 2021 Proceedings

Track 20: Management of digital processes \& architectures

\title{
The Status Quo of Process Mining in the Industrial Sector
}

Sebastian Dunzer

Friedrich-Alexander-Universität Erlangen-Nürnberg

Sandra Zilker

Friedrich-Alexander-Universität Erlangen-Nürnberg

Emanuel Marx

Friedrich-Alexander-Universität Erlangen-Nürnberg

Valentin Grundler

Friedrich-Alexander-Universität Erlangen-Nürnberg

Martin Matzner

Friedrich-Alexander-Universität Erlangen-Nürnberg

Follow this and additional works at: https://aisel.aisnet.org/wi2021

Dunzer, Sebastian; Zilker, Sandra; Marx, Emanuel; Grundler, Valentin; and Matzner, Martin, "The Status Quo of Process Mining in the Industrial Sector" (2021). Wirtschaftsinformatik 2021 Proceedings. 2. https://aisel.aisnet.org/wi2021/EManagementofdigitalprocesses20/Track20/2

This material is brought to you by the Wirtschaftsinformatik at AIS Electronic Library (AISeL). It has been accepted for inclusion in Wirtschaftsinformatik 2021 Proceedings by an authorized administrator of AIS Electronic Library (AISeL). For more information, please contact elibrary@aisnet.org. 


\title{
The Status Quo of Process Mining in the Industrial Sector
}

\author{
Sebastian Dunzer, Sandra Zilker, Emanuel Marx, Valentin Grundler, Martin Matzner \\ Friedrich-Alexander-Universität Erlangen-Nürnberg, Lehrstuhl für Digital Industrial Service \\ Systems, Nürnberg, Germany \\ \{sebastian.dunzer, sandra.zilker, emanuel.marx, \\ valentin.grundler, martin.matzner\}@fau.de
}

\begin{abstract}
Since process mining started to reveal the potential of event logs, it has been applied in various process settings ranging from healthcare to production. Every single setting poses its challenges to process analysts who want to apply process mining. The present paper aims at minimizing such challenges for enterprises in the industrial sector by providing a coherent overview of existing cases. Our systematic literature review relates each production form and layout from existing case studies to the applied process mining type. Further, we use Porter's value chain to distinguish operations from other primary and support activities in production. We present the application of process mining, particularly for the production process and the primary activities other than the operations. The results indicate that process mining fits best with cellular production layouts with batch or line production processes.
\end{abstract}

Keywords: process mining, production, production form, production layout

\section{Introduction}

Recent developments enable companies to use data from information systems to analyze their operations [1]. One of these developments is process mining. Process mining creates insights from event logs captured by process-aware information systems (PAIS) [2]. PAIS track all steps that are required to conduct a particular workflow [3]. The range of existing PAIS includes, e.g., manufacturing execution systems and enterprise resource planning systems. The resulting event logs must uniquely identify process instances, the according events, and their respective execution order [4]. With this information, process mining generates knowledge from event logs by utilizing a combination of data mining and business process management methods [2].

Process mining can be used for different kinds of processes, such as economic activities. Economic activities can be divided into different sectors based on the activity's characteristics [5]. Since the production processes of tangible goods are at the center of the industrial or secondary sector, their optimization has been of particular interest to researchers and practitioners [6]. The scientific literature contains a multitude of defi- 
nitions for the term production. However, there is a general understanding that production describes the transformation of input, such as raw materials or semi-finished products, combined with immaterial input, such as labor or know-how, into output, like finished goods or services [7]. Manufacturing, on the other hand, typically uses raw materials as input. The term production is more general than the term manufacturing and will be used primarily in this paper. However, both terms are often used interchangeably [8].

In contrast to administrative processes, production processes differ significantly in separate organizations. The variety of production processes ranges from the continuous flow and highly standardized processes [9], e.g., oil refinement, to order-based production with high customization [10], e.g., aircraft. Thus, the production follows distinct paradigms and utilizes different job-shop layouts.

The literature defines several goals for a company's success related to the production processes. These are, e.g., minimizing the throughput time, costs, or downtimes. To realize those goals, e.g., by eliminating bottlenecks, companies must know what their production processes look like [11]. Therefore, process mining, specifically process discovery, aims at generating a process model based on the event log data from a production process. Besides discovering processes, process mining also checks whether a particular process conforms to the to-be process and further enables process enhancement $[2,12]$. However, the differences regarding standardization impede recommending general approaches to analyze and optimize production processes.

Recent research evaluated process mining in several settings, e.g., oncology [13], elderly care [14], and health care in general $[15,16]$. Even though different views on enterprises, including production firms, have been examined, e.g., the supply chain [17], we find production itself is not at the center of interest [18].

Based on this, we provide a coherent overview of the status quo of process mining in the context of production, i.e., the industrial sector, by answering the following research question:

RQ: $\quad$ Which type of process mining was applied to the different production layouts and forms?

We support the general understanding of process mining in production by providing an overview that links the form of production and the production layout to the applied process mining types from existing case studies. Therefore, we follow Webster and Watson's [19] and Kitchenham's [20] guidelines for conducting a systematic literature review. To cover the entire scope of production enterprises' activities, we employ Porter's value chain to distinguish between activities [21]. We use a concept-matrix to present the results of the literature review. The matrix classifies existing process mining studies regarding their position in the value chain and their production layout and form. We summarize the identified process mining application shortly to help practitioners find related cases to their own potential process mining use case. As our contribution to academia, we theorize findings from the existing literature and propose future research. 
The paper is structured as follows. Section 2 presents the relevant theoretical background on process mining, Porter's value chain, and the production setting. Afterward, we present the underlying method. In Section 4, we outline the results and roughly summarize the identified process mining studies. The subsequent section discusses the review results, proposes future research for process mining in the industrial sector, and states limitations to this study. The closing section summarizes the paper.

\section{Theoretical Background}

\subsection{Types of Process Mining}

Process mining aims to "discover, monitor and improve real-world processes (i.e., not assumed processes) by extracting knowledge from event logs readily available in today's (information) systems" [2, p.1]. By exploiting this information using different techniques, one can gain insights into processes that would not be possible by following traditional process management approaches. To provide these techniques, Process Mining is a field of research that sits between data mining as well as business process management. Based on that, the present literature distinguishes three process mining types [2]. First, process discovery generates process models from an event log. Discovery is useful to gain insights into patterns that may not have been known by process participants. To examine an event log in-depth, analysts filter for specific patterns or data attributes. Second, conformance checking reveals whether and how process behavior differs from given models, e.g., process models, organizational models, and policies. Conformance checking can compare planned processes to their respective actual processes, whereby it can unveil errors in the planned and real process. Third, enhancement gathers additional information from event logs and adds these to a process model to facilitate process optimization [12].

\subsection{Porter's Value Chain}

The processes examined with process mining differ significantly regarding complexity, variety, and $t$ application areas depending on the company and related activities. We use Porter's [21] value chain to distinguish these activities based on their value chain positioning. Porter classifies activities within value chains into two main groups.

First, primary activities reflect the core business of a firm. These consist of "activities associated with transforming inputs into the final product form. In production, these activities comprise machining, packaging, assembly, equipment maintenance, testing, printing, and facility operations" [21]. Therefore, these activities are in- and outbound logistics, operations, marketing and sales, and service [21]. We further distinguish operations from the other primary activities, as it comprises the production itself. The support activities increase the effectiveness of at least one primary activity. Porter divides these into procurement, technology development, human resource management, and firm infrastructure [21]. However, we do not focus on support activities in the underlying paper as they are not directly related to the form of production. 


\subsection{Forms of Production}

The existing literature proposes several ways to classify forms of production. For instance, based on the production volume, the variety of produced goods, or the physical organization of machines or workforce. In the following, we characterize the different production process types concerning volume, variety, and production-layout.

Production processes differ in variety and volume of produced goods and range from a high level of customization and a low volume to high standardization with a high volume. The four existing archetypes for this range are defined as follows. A job process handles a wide variety of produced goods with a high degree of customization and a low production volume, e.g., ships [10]. This type of production process requires a high level of flexibility from both the workforce and machinery [9]. In contrast to job processes, a batch process handles high volumes of similar or related products in batches, e.g., bakery goods [22]. When a firm produced the desired number of products from one batch, it reconfigures the production process for the next batch [9]. Line processes are geared towards standardized products with high production volumes, e.g., cars. Such processes are at the center of optimizing material handling, automation, and cost savings [9, 23]. Lastly, continuous flow processes are highly standardized highvolume processes without any customization, e.g., oil refinement. Raw materials like ores, liquids, or gases flow through such processes. Theoretically, these processes never need to be stopped if enough raw, auxiliary, and operating materials are provided, and machines do not have any outages [9].

In addition to the form of production, we distinguish the production layout, i.e., the physical arrangement of operations, facilities, and machines. Overall, there are three types of production layouts, the job-shop, the cellular, and the assembly-line layout. The job-shop layout is based on the production process from craftwork. One person is responsible for one item. Hence, the shop floor is designed to enable the free assignment of a producible object to a person or a machine that conducts the complete production process. The flexibility to produce distinct goods is very high but restricts the production volume. Therefore, line processes or continuous-flow processes are considered infeasible in the job-shop layout. Concerning the cellular layout, the shop floor comprises independent cells. Each cell, i.e., the assigned machines and workers, is responsible for a specific task. Therefore, the product moves along those cells where each individual step is then performed [24]. Compared to the job-shop layout, cellular layouts are less flexible regarding the produced goods but handle more significant production volumes. In an assembly line layout, all materials, machines, and workers are arranged along one line of production. The directed material flow and the resulting fixed order increase the standardization, but job processes become infeasible in an assembly-line layout [24].

\section{Method}

To answer the research questions, we conduct a systematic literature review following Webster and Watson [19] and Kitchenham [20]. Our overall goal is the presentation of the status quo in a specific area. We analyze the progress and identify potential topics 
for future research in this area. Thus, our review belongs to the descriptive reviews [25, 26]. The systemic literature review begins with the definition of the review scope [27].

The focus of our research is on publications of process mining applications in the industrial sector. The goal of our review is to investigate what progress has been made so far in the area mentioned above and how far there is a relationship between the chosen process mining type and the characteristics of the production process. Since we evaluate the current state of research, our review's organization is rather conceptual than historical or methodological. Due to the descriptive nature of our review, the perspective we take is neutral. Given that we present our findings in this conference paper, our review's audience consists of scholars, although it provides guidance for practitioners as well. Regarding coverage, Müller-Bloch and Kranz [28] argue that "while it may be argued that literature reviews should always be exhaustive, we reckon that analyzing all prior research is neither always possible nor economical and necessary". Consequently, the coverage of our review is representative, as is appropriate for descriptive literature reviews. The literature search was conducted on Scopus, EBSCO, and Proquest to cover a wide range of relevant academic journals and conferences. After Proquest, as the third database consulted, only added one paper that we considered relevant, we see this a proof of high coverage of existing releases. The search string that we used is

\section{("process mining" OR "workflow mining" OR "trace mining") AND (manufactur* OR production OR factory OR machinery)}

In addition to scientific publications, case studies provided by software vendors or companies using process mining are a relevant source of information about industrial applications. For this reason, we consulted a case study database supplied by the "IEEE Task Force on Process Mining" [29] as the second part of our literature search. Within this database, companies and process mining appliers publish their use cases by giving information about business problems, implemented process mining techniques, applied tools, and contributions of the analysis to the business processes. The chair of task force founder van der Aalst then checks these papers for completeness and relevance to ensure data quality.

Already cleaned for duplicates, our initial search resulted in 490 hits, from which 290 trace back to Scopus, 103 to EBSCO, 58 to Proquest, and 39 to IEEE. After removing 54 duplicates, we screened these papers' titles and abstracts. Typical causes for exclusion at this stage were: (1) A missing focus on presenting a practical application of process mining. For instance, if a case describes the process mining potential only theoretically or if a case only uses simulated or generated production data. (2) A missing focus on a primary activity in economic production, (3) insufficient assignability to an organizational form of production. In the first round of analysis, 365 papers were removed from the dataset, leaving 71 articles in the review scope. We performed a forward and backward search afterward [19]. Therefore, we looked up the identified papers on Google Scholar and analyzed the titles and abstracts from the identified papers' references and the articles that cited a previously identified paper. Whenever a paper dealt with a process mining application in an industrial setting, we included it in the 
review. During this process, we added eight papers to our study. Next, we checked the full text of these papers, having the selection criteria mentioned above in mind. After removing 26 irrelevant articles and 13 articles to which we did not get access, the final set comprises 40 articles, including 30 specific applications.

\section{$4 \quad$ Results}

To classify the results, we created a concept matrix [19] based on the concepts described in Section 2. The first dimension is the value chain positioning, i.e., according to primary and secondary activities suggested by Porter [21]. The second and third dimensions are the production process type and the production layout. Lastly, we distinguish between the process mining type used in each case. Table 1 presents the resulting concept matrix.

\subsection{Applications in Operations}

We identified 21 applications that apply process mining in production processes. The respective form and layout of production for each of them are depicted in Figure 1. In general, every case uses process discovery, eight cases utilize conformance checking, and only two case employs a form of enhancement.

Rozinat et al. [30] outline how a wafer scanner producer conducted a process mining project. Wafer scanners consist of various building blocks. During their production, the scanners are assembled at the plant, then disassembled, shipped to the customer, and finally re-assembled. The authors constructed a process model based on the test logs with process discovery. They found process optimization potential by suggesting performing test activities earlier than usually intended. Park et al. [10] examine analysis techniques from process mining in make-to-order production, such as shipbuilding and aviation. The paper examines process data from Hyundai Heavy Industries Co. The study determines the workload and delay of production processes by comparing the optimized planned process with the actual process. Therefore, they deploy performance- and time-perspective conformance checking in shipbuilding. Ruschel et al. [31] discover Bayesian Networks in a Brazilian automotive company. The Bayesian Networks can estimate the process cycle time based on a defined availability and cost functions. Finally, they optimize the maintenance schedule to improve machine run time.

Lee et al. [32] and Park et al. [33] aim to gain insights into the assembly and the after-assembly block production process of Daewoo Shipbuilding \& Marine Engineering. Due to the absence of contextual data in the log, the analysis employs process discovery for identifying undesired process patterns. Pospíšil et al. [34] describe how a Czech door manufacturer uses process mining to predict production times of orders. Their approach employs process discovery to build accurate, evidence-based simulation models to predict performance and recommend future actions. 
Table 1. Overview on applications of process mining by production layout, production process, and their value chain positioning.

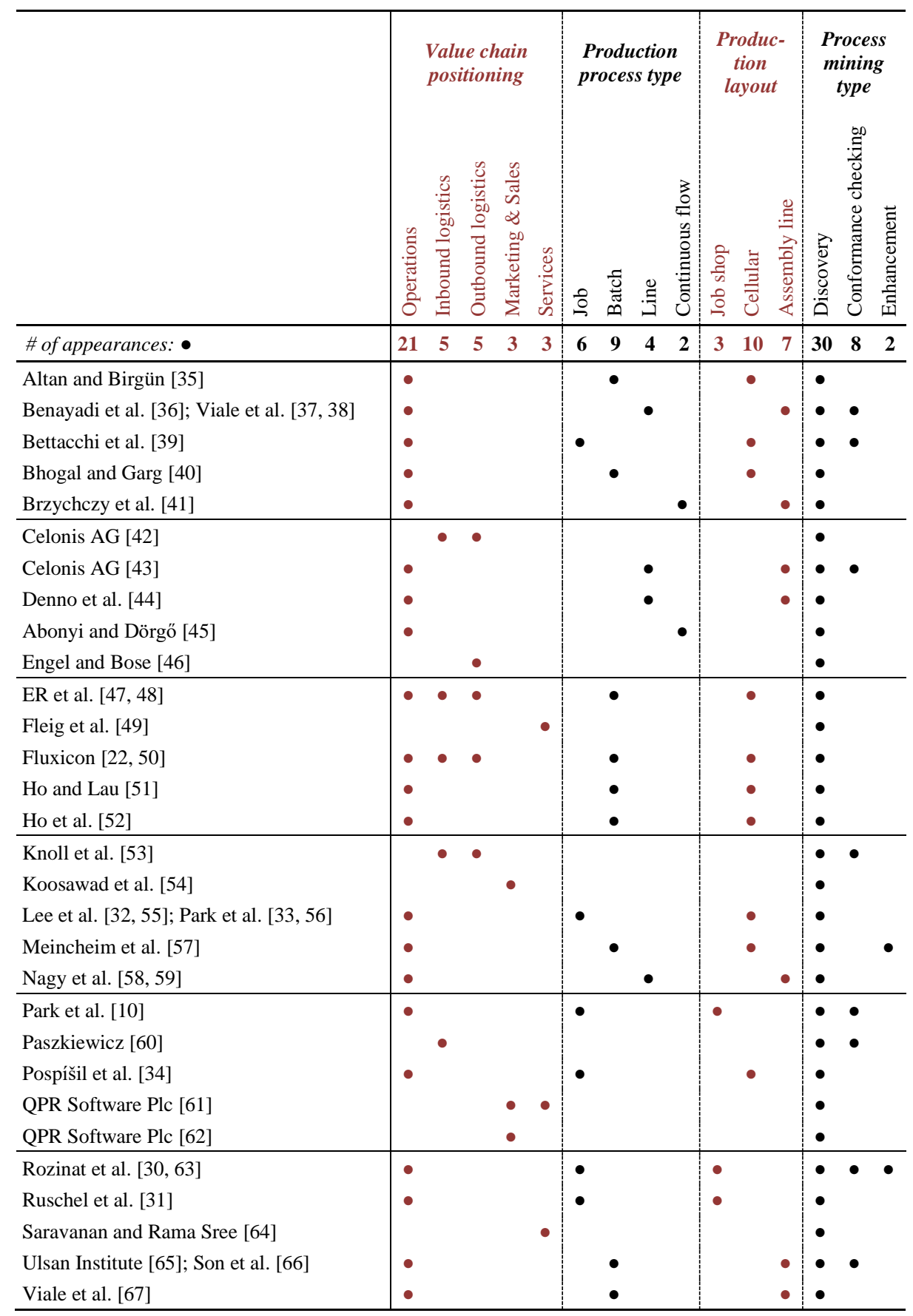




\begin{tabular}{|c|c|c|c|c|}
\hline \multirow{2}{*}{$\begin{array}{l}\text { D: Discovery } \\
\text { C: Conformance } \\
\text { checking } \\
\text { E: Enhancement }\end{array}$} & \multicolumn{4}{|c|}{$\begin{array}{l}\text { Production process type } \\
\text { (variety/volume of produced goods) }\end{array}$} \\
\hline & $\begin{array}{c}\text { Job } \\
\text { process } \\
\text { (fully customized; } \\
\text { low volume) }\end{array}$ & $\begin{array}{c}\text { Batch } \\
\text { process } \\
\text { (multiple products; } \\
\text { low or moderate } \\
\text { volume) }\end{array}$ & $\begin{array}{c}\text { Line } \\
\text { process } \\
\text { (few products; } \\
\text { higher volume) }\end{array}$ & $\begin{array}{c}\text { Continuous flow } \\
\text { process } \\
\text { (high standardiza- } \\
\text { tion; high volume) }\end{array}$ \\
\hline $\begin{array}{r}\text { Job shop } \\
\text { production } \\
\text { (product is flexibly } \\
\text { assigned to machine } \\
\text { workers) }\end{array}$ & $\begin{array}{l}\text { Wafer scanners } \\
\text { D, C, E [30, 63] } \\
\text { Ships } \\
\text { D, C [10] } \\
\text { Maintenance } \\
\text { D [31] }\end{array}$ & $\begin{array}{l}\text { No case study } \\
\quad \text { found }\end{array}$ & Not feasible & Not feasible \\
\hline 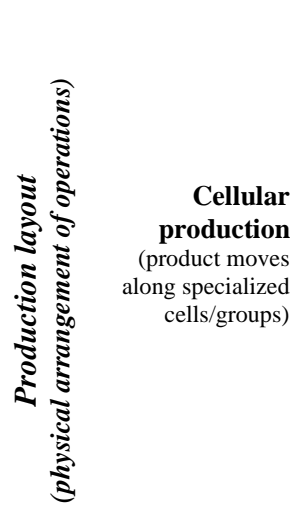 & $\begin{array}{l}\text { Ships } \\
\text { D [32, 33, 55, 56] } \\
\text { Doors } \\
\text { D [34] } \\
\text { Coffee machine } \\
\text { D, C [39] }\end{array}$ & $\begin{array}{l}\text { Control panels } \\
\text { D, E [57] } \\
\text { Shoe parts } \\
\text { D [47, 48] } \\
\text { Micro-precision } \\
\text { parts D [22, 50] } \\
\text { Electronic prod- } \\
\text { ucts D [51] } \\
\text { Sliders } \\
\text { D [52] } \\
\text { Propellers } \\
\text { D [35] } \\
\text { Maintenance } \\
\text { D [40] }\end{array}$ & $\begin{array}{l}\text { No case study } \\
\quad \text { found }\end{array}$ & Not feasible \\
\hline $\begin{array}{r}\text { Assembly line } \\
\text { production } \\
\text { (product moves } \\
\text { from workstation to } \\
\text { workstation) }\end{array}$ & Not feasible & $\begin{array}{l}\text { Computer parts } \\
\text { D, C [65, 66] } \\
\text { Semiconductors } \\
\text { D [67] }\end{array}$ & $\begin{array}{l}\text { Automotive parts } \\
\text { D, C [43] } \\
\text { Electronic chips } \\
\text { D, C [36-38] } \\
\text { Automotive as- } \\
\text { sembly D [44] } \\
\text { Coils } \\
\text { D [58, 59] }\end{array}$ & $\begin{array}{l}\text { Mining machine } \\
\text { operation D [41] } \\
\text { Oil refinement } \\
\text { D [45] }\end{array}$ \\
\hline
\end{tabular}

Figure 1. Distribution of process mining applications in operations by production process type and production layout.

The coffee machine manufacturer Nuova Simonelli validates and analyses their production process with process mining [39]. The company has six production lines; each of them is divided into stations that serve specific purposes. In this case, the approach is to apply five different discovery algorithms. Subsequently, the analysts use conformance checking to show which of the algorithms leads to the most accurate resulting model. The company could then optimize their process regarding the recommendations derived from the discovered process models.

Meincheim et al. [57] describe how WEG, a Brazilian energy solutions provider and electric motor producer, applies process mining. The company conducts the production planning for each custom control panel. After that, they set up a production route for one batch. The production operators decide which machines take part in the assembling. 
The authors use discovery to analyze the as-is process and afterward enhance the generated models with additional insights from further analysis of the activity frequencies and variants. Thus, this study is the only application that employs enhancement. The authors show that production operators rearrange the shop floor according to currently available resources instead of waiting for the optimal machine assignment. The shoe manufacturer PT. XYZ Indonesia uses process mining to optimize production planning and warehouse management processes [47, 48]. Using discovery, the company identified deviations between their demand prognosis and the actual demand. Such deviations cause errors in production planning and require resource-intensive rescheduling activities. Veco aims to reduce lead time in its production plant for micro-precision parts [22, 50]. The main challenge in their production is that only the finished product can be assessed regarding quality. To get early feedback, the company desires to keep the production cycles short. Veco identified which workstations cause the most delays by visualizing the as-is processes with discovery. The company could improve the flexibility in departments involved in later stages of the production. Ho et al. [52] implemented process discovery with neural networks and fuzzy logic at a slider manufacturer to reduce rework and scrap rates. Ho and Lau [51] implemented real-time process analysis with process discovery from various data sources at a computer electronics producer. The overall objective was to reduce rework. One study uses process discovery with data from a manufacturing system to increase the transparency in propeller production during the implementation of new production technologies [35]. In [40], the authors apply process discovery, including a variant analysis, to examine rework activities and machinery breakdown. To improve future executions, the authors design a new model tobe model from the discovered model.

Son et al. [66] and Ulsan Institute [65] apply process mining at Samsung Electro Mechanics. Although process discovery discloses a high variation in machine utilization, conformance checking only identifies minor deviations between the actual and planned process. Today, Samsung uses the information to balance the machine utilization. STMicroelectronics, a semiconductor producer from Switzerland, utilizes process mining to gain transparency [67]. The production process consists of more than a thousand process variants. Because of the process's complexity, modifying it based on a customer's demand is prone to errors. Therefore, STMicroelectronics wants to discover accurate process models based on event logs from the production processes.

Eissmann, a German automotive supplier, uses process mining to digitize its processes [43]. Especially the purchase-to-pay, the master data management, and the production processes are continuously monitored. Besides, Eissmann can assure quality in labor-intensive process steps by revealing bottlenecks with discovery, e.g., when working with leather whose processing needs to be finished after a fixed amount of time. Denno et al. [44] apply process discovery based on genetic programming to incorporate probabilistic and causal information into the discovered model. In their evaluation, the discovered model is used for scheduling. Nagy et al. [59] apply several process mining techniques in coil manufacturing to find distributions of faulty products in the entire production. In [58], the authors further develop their process mining application for real-time analysis. Three related studies at STMicroelectronics strive to create largescale process models for electronic chip manufacturing [36-38]. These cases employ 
different discovery strategies extended by stochastic approaches, time data, and sequence alignment to generate high-quality process models. One study investigates the application of process mining in mining operations to identify opportunities for operational improvement [41]. It describes the first application of process mining to investigate the working process of a roof bolter operating in an underground mine. Abonyi and Dörgö [45] use process mining at an industrial delayed-coker plant to identify frequent operations that lead to alarms. Their objective was to lower the number of alarms raised during production.

\subsection{Application in Primary Activities other than Operations}

Nine additional cases show process mining applications in primary activities other than production operations.

Four of these cases employ process mining in logistics processes. Engel et al. [46] analyze the ordering, delivery, and invoicing at a consumer goods producer. The company wanted to identify the items that take the longest until they can be delivered. In this paper, only a subset of the process data was available, which aggravates drawing generalizable conclusions. Neste oil is an oil and gas provider [42]. They analyzed their procurement and logistic processes with discovery and conformance checking to identify deviations. Knoll et al. [53] examine the inbound logistics for the mixed-model assembly line at a German car manufacturer, whereby they discovered unknown process paths and facilitated process transparency. Paszkiewicz [60] examines the inventory management of a mattress producer with an emphasis on conformance checking. The authors checked conformance to a process model as well as policies. Based on the results, the firm organized training for storekeepers and rearranged warehouse management.

Three of the identified case studies examine production-related service processes. MG Motors, a car producer, operates a sales and service unit in India [64]. The authors evaluate fifty troubleshooting methods of motorcycle repair with process mining. The company discovers a process model from data that helps mechanics during process execution. Finally, the authors conclude that unstructured processes pose a challenge to process mining. Vaisala, a producer of measuring instruments and sensors, used discovery to visualize support and repair processes [61]. The gathered insights enable the company to support change management through fast verification of process actions. In another case, the authors apply process mining in the implementation of an enterprise resource planning system in a production setting [49]. They find that process mining can aid in the selection of a process template from process databases such as the SAP Best Practices Explorer.

Additional two cases focused on the application in marketing and sales. QPR Software Plc $[61,62]$ analyzes the relation between data from opportunity processes and delivery processes in the PAIS of a steel construction company. The case study compares the planned sales to the numbers from the discovered delivery processes. The unveiled deviations led to the adjustment of the planned process. Koosawad [54] shows how process mining can help to improve the efficiency of a car manufacturer's sales process. The company analyzes the participation of each employee in a car sale. An in- 
depth discovery analysis unveiled that some employees perform better than others. Subsequently, the company established best practices by analyzing the procedures of successful sellers.

\section{Discussion}

\subsection{Findings}

We found three main areas of application for production companies that use process mining in their operative processes. First, companies try to gather information about repair and rework steps in the production process. Previous research shows how process mining can identify repair activities as bottlenecks and root-cause for disadvantageous machine disposition. Second, quality assurance as an area of interest for process mining is outlined. Third, the largest proportion of applications concerns machine utilization and workstation efficiency. We conclude that several companies could optimize the performance of these production processes with process mining.

The prevalent production setting for process mining is the batch process with a cellular production layout. In contrast to line and continuous-flow processes, these production forms require resource and workstation allocation relatively often. This hypothesis is supported by the high number of process mining applications that attempt to optimize machine utilization and workstation efficiency. Most of these studies use filtering for data attributes to identify bottlenecks in the production process. Consequently, the firms can redesign the processes based on these insights.

Except for continuous-flow processes, process discovery can identify repair and rework in a similar manner by creating Petri nets or Fuzzy models [45, 51]. Due to the rearrangement of the job shop layout with every production process step, repair and rework becomes a costly problem when temporary solutions need to be installed for reworking a previous process step. Hence, in such settings, users apply process mining to identify potential sources of rework.

Process mining can potentially improve continuous-flow processes [41]. However, both identified case studies had difficulties applying process mining. The event logs contain noise that aggravates process mining [45]. Furthermore, there is no logical termination of the process, processes run for a long time, and the time span between events is longer than in many other business processes. Hence, these studies rather aim at creating process models of their production rather than creating specific opportunities for business improvement. In such settings, the transferability of process mining is not given yet, and the applicability of conformance checking and enhancement are impeded by the absence of existing process models.

Process mining in primary value chain activities other than operations concerns sales and opportunity management [54, 61, 62], support and repair services [61, 64], and logistics $[33,42,46,53]$. In some of these cases, the companies use process mining in support activities as well. Except for the enterprises that use process mining in logistics, which also use conformance checking, companies tend to apply process discovery exclusively. 
Despite the difference in each of the process mining applications, we see a trend regarding the complexity of a production process and the types of process mining. Firms producing complex goods, such as ships, wafer scanners, or cars, are more likely to apply conformance checking or enhancement techniques than companies producing goods in large quantities, e.g., semiconductors, micro-precision parts, propellers. However, this is more of a general trend than a clear observation.

Additionally, Rozinat et al. [30] note that their findings were possibly already out of date because they did not apply to the next product generations. Therefore, such process analysis should be carried out iteratively to provide valuable insights.

\subsection{Future Research}

Systematic literature reviews should draw implications from previous research for the future, according to Webster and Watson [19]. Therefore, we outline open topics for future research that should be discussed regarding process mining in the industrial sector.

We found that every process mining application includes process discovery, whereas only a few of the identified cases apply other types of process mining. This dominance of discovery indicates that companies perceive it as the most applicable or useful type of process mining. In most cases, the high-level insights generated through discovery seem to satisfy the expectation of process mining users already. Due to the imbalance of process mining types, an in-depth analysis of process mining users' expectations could bear valuable knowledge to create new process mining methods for production processes.

Conformance checking is only rarely represented throughout the process mining cases. Additionally, enhancement is only applied once in the identified case studies. Both conformance checking and enhancement require a process model for their application. We assume the scope of process models for process planning or as workflow instructions differs from the available event logs regarding the level of detail. Perhaps event logs represent a much finer grain of detail than the rather high-level process models which are created by humans. Companies would need to create process models with a similar scope as the event log from production PAIS. This finding is supported by the fact that only two case studies use process models, which were not created during the project itself, i.e., through process discovery. Those two application cases take place in companies with an assembly-line production layout. Due to the design of an assembly line, the process flow rarely changes. Most products pass through similar process steps in a similar order. Thus, firms with an assembly line can create more detailed production process models with reasonable effort. We believe research and practice would profit from studies on existing production process modeling practices. A deeper understanding of the scope of the process in these areas might facilitate more target-oriented process analyses. Furthermore, the difference in the degree of detail in manually modeled processes and existing event logs should be solved by either aggregation techniques regarding events or modeling at the event-level of a process.

Even though the quality and availability of data are presumably higher in assemblyline layouts, companies who apply process mining mostly operate a cellular production 
layout. We assume that companies want to apply process mining in cases that seem more complex and that can take different paths in a production process. With a cellular layout, it is presumably less likely that the processes are planned as accurately as in assembly-line layouts. Additionally, the production is more standardized than in settings that use the job-shop layout. Consequently, PAIS can protocol process steps within the cells. Still, the finding requires a deeper analysis of the actual reasons.

We believe that for the progress of process mining in production, an analysis of the maturity of the process mining project, the production under examination, and the data quality might provide valuable insights. A descriptive and prescriptive maturity model can support companies and researchers when starting or further developing their process mining projects in a production setting [68].

\subsection{Limitations}

Although we conducted this research with our best efforts, the paper underlies some limitations. First, while we included the most frequent keywords in the search string, we might have omitted relevant papers or case studies. We further included productionrelated keywords in the search, which might have caused the omission of articles that do not explicate the area of application. However, we tried to minimize the risk by conducting forward and backward searches. Second, the relatively low number of existing practical reports and case studies aggravates the findings' generalizability. Still, the identified papers cover different industries and can thereby grant some level of generalizability. Third, the process mining studies from practice are mostly provided by process mining vendors, i.e., Celonis AG, Fluxicon, and QPR Software. Thus, these reports are probably handpicked regarding the success of the process mining application. However, since the IEEE Taskforce added the cases to their database, we believe that the studies contain valuable information about where successful process mining applications in the industrial sector were conducted.

\section{Conclusion}

This paper presents the results of a systematic literature review on applications of process mining in the industrial sector. Therefore, we provide a rough overview of the existing process mining studies. We show that most companies who apply process mining make use of cellular production layouts. Regarding the process mining type, analysts implement discovery in every case, whereas conformance checking was applied only in assembly-line production layouts with process models that existed prior to the process mining project. Only one study applied an enhancement technique to amend a beforehand discovered process model. Further, our findings show that enterprises in the production industry apply process mining in several business areas, i.e., logistics, delivery, quality management, sales, and opportunity management. 


\section{References}

1. Urbach, N., Ahlemann, F., Böhmann, T., Drews, P., Brenner, W., Schaudel, F., Schütte, R.: The impact of digitalization on the IT department. Business \& Information Systems Engineering 61, 123-131 (2019)

2. van der Aalst, W. et al.: Process Mining Manifesto. In: Daniel, F., Barkaoui, K., Dustdar, S. (eds.) Business Process Management Workshops, 99, pp. 169-194. Springer Berlin Heidelberg, Berlin, Heidelberg (2012)

3. van der Aalst, W., Reijers, H.A., Weijters, A.J.M.M., van Dongen, B.F., Alves de Medeiros, A.K., Song, M., Verbeek, H.M.W.: Business process mining: An industrial application. Information Systems 32, 713-732 (2007)

4. Jans, M., Soffer, P., Jouck, T.: Building a valuable event log for process mining: an experimental exploration of a guided process. Enterprise Information Systems 13, 601-630 (2019)

5. Kenessey, Z.: The primary, secondary, tertiary and quaternary sectors of the economy. Rev Income Wealth 33, 359-385 (1987)

6. Alexander, M.: Six Sigma: The Breakthrough Management Strategy Revolutionizing the World's Top Corporations. Technometrics 43, 370 (2001)

7. Bates, J.A., Parkinson, J.R.: Business economics. Blackwell, Oxford (1971)

8. Kalpakjian, S., Schmid, S.: Manufacturing engineering and technology. Prentice Hall, New York (2010)

9. Krajewski, L.J., Malhotra, M.K., Ritzman, L.: Operations Management: Processes and Supply Chains. Pearson, Harlow (2019)

10. Park, M., Song, M., Baek, T.H., Son, S., Ha, S.J., Cho, S.W.: Workload and Delay Analysis in Manufacturing Process Using Process Mining. In: Bae, J., Suriadi, S., Wen, L. (eds.) Asia Pacific Business Process Management, 219, pp. 138-151. Springer International Publishing, Cham (2015)

11. Ishaq Bhatti, M., Awan, H.M., Razaq, Z.: The key performance indicators (KPIs) and their impact on overall organizational performance. Qual Quant 48, 3127-3143 (2014)

12. Mannhardt, F.: Multi-perspective process mining. Eindhoven (2018)

13. Kurniati, A.P., Johnson, O., Hogg, D., Hall, G.: Process mining in oncology: A literature review. Proceedings of the 6th International Conference on Information Communication and Management (ICICM), 291-297 (2016)

14. Farid, N., Kamps, M. de, Johnson, O.: Process Mining in Frail Elderly Care: A Literature Review. Proceedings of the 12th International Joint Conference on Biomedical Engineering Systems and Technologies, 332-339 (2019)

15. Rojas, E., Munoz-Gama, J., Sepúlveda, M., Capurro, D.: Process mining in healthcare: A literature review. Journal of Biomedical Informatics 61, 224-236 (2016)

16. Ghasemi, M., Amyot, D.: Process mining in healthcare: a systematised literature review. International Journal of Electronic Healthcare 9, 60 (2016)

17. Jokonowo, B., Claes, J., Sarno, R., Rochimah, S.: Process Mining in Supply Chains: A Systematic Literature Review. International Journal of Electrical and Computer Engineering (IJECE) 8 (2018)

18. Nugroho Yahya, B.: The Development of Manufacturing Process Analysis: Lesson Learned from Process Mining. Jurnal Teknik Industri 16 (2014)

19. Webster, J., Watson, R.T.: Analyzing the Past to Prepare for the Future: Writing a Literature Review. MIS Q 26, xiii-xxiii (2002)

20. Kitchenham, B.: Procedures for Performing Systematic Reviews. Keele University, 1-26 (2004) 
21. Porter, M.E.: Competitive advantage: creating and sustaining superior performance. Free Press, New York (1985)

22. Fluxicon BV: Leveraging human process knowledge via process mining (2016)

23. Fandel, G., Fistek, A., Stütz, S.: Produktionsmanagement. Springer (2009)

24. Grabner, T.: Operations Management. Springer, Wiesbaden (2017)

25. Paré, G., Trudel, M.-C., Jaana, M., Kitsiou, S.: Synthesizing information systems knowledge: A typology of literature reviews. Information \& Management 52, 183-199 (2015)

26. Okoli, C.: A Guide to Conducting a Standalone Systematic Literature Review. Communications of the Association for Information Systems 37 (2015)

27. Cooper, H.M.: Organizing knowledge syntheses: A taxonomy of literature reviews. Knowledge in Society 1, 104-126 (1988)

28. Müller-Bloch, C., Kranz, J.: A Framework for Rigorously Identifying Research Gaps in Qualitative Literature Reviews. In: Proceedings of the 23rd European Conference on Information Systems (ECIS) (2015)

29. IEEE CIS Task Force on Process Mining: Process Mining Case Studies, https://www.win.tue.nl/ieeetfpm/doku.php?id=shared:process_mining_case_studies (2019)

30. Rozinat, A., Jong, I.S.M. de, Gunther, C.W., van der Aalst, W.M.P.: Process Mining Applied to the Test Process of Wafer Scanners in ASML. IEEE Transactions on Systems, Man, and Cybernetics, Part C (Applications and Reviews) 39, 474-479 (2009)

31. Ruschel, E., Santos, E.A.P., Loures, E.d.F.R.: Establishment of maintenance inspection intervals: an application of process mining techniques in manufacturing. J Intell Manuf 467, 103 (2018)

32. Lee, S.-k., Kim, B., Huh, M., Cho, S., Park, S., Lee, D.: Mining transportation logs for understanding the after-assembly block manufacturing process in the shipbuilding industry. Expert Systems with Applications 40, 83-95 (2013)

33. Park, J., Lee, D., Zhu, J.: An integrated approach for ship block manufacturing process performance evaluation: Case from a Korean shipbuilding company. International Journal of Production Economics 156, 214-222 (2014)

34. Pospíšil, M., Mates, V., Hruška, T., Bartík, V.: Process Mining in a Manufacturing Company for Predictions and Planning. International Journal on Advances in Software 6, 283-297 (2013)

35. Altan, Z., Birgün, S.: Using Process Mining Approach for Machining Operations. In: Proceedings of the International Symposium for Production Research, pp. 452-464 (2019)

36. Benayadi, N., Le Goc, M., Bouché, P.: Using the Stochastic Approach Framework to Model Large Scale Manufacturing Processes. In: Proceedings of the Third International Conference on Software and Data Technologies (ICSOFT), pp. 186-191 (2008)

37. Viale, P., Benayadi, N., Le Goc, M., Pinaton, J.: Modeling Large Scale Manufacturing Process from Timed Data - Using the TOM4L Approach and Sequence Alignment Information for Modeling STMicroelectronics' Production Processes. In: Proceedings of the 12th International Conference on Enterprise Information Systems (ICEIS), pp. 129-138 (2010)

38. Viale, P., Benayadi, N., Le Goc, M., Pinaton, J.: Discovering Large Scale Manufacturing Process Models from Timed Data - Application to STMicroelectronics' Production Processes. In: Proceedings of the 5th International Conference on Software and Data Technologies (ICSOFT), pp. 227-235 (2010)

39. Bettacchi, A., Polzonetti, A., Re, B.: Understanding Production Chain Business Process Using Process Mining: A Case Study in the Manufacturing Scenario. In: Lecture Notes in Business Information Processing, pp. 193-203. Springer (2016) 
40. Bhogal, R., Garg, A.: Anomaly Detection and Fault Prediction of Breakdown to Repair Process Using Mining Techniques. In: Proceedings of the International Conference on Intelligent Engineering and Management (ICIEM), pp. 240-245 (2020)

41. Brzychczy, E., Gackowiec, P., Liebetrau, M.: Data Analytic Approaches for Mining Process Improvement-Machinery Utilization Use Case. Resources 9, 17 (2020)

42. Celonis AG: Big Data is the new oil (2017)

43. Celonis AG: Big data-powered tuning for fast and secure processes (2017)

44. Denno, P., Dickerson, C., Harding, J.A.: Dynamic Production System Identification for Smart Manufacturing Systems. Journal of Manufacturing Systems 48 (2018)

45. Abonyi, J., Dörgő, G.: Process mining in production systems. In: Proceednings of the 23rd IEEE International Conference on Intelligent Engineering Systems (INES), pp. 267-270 (2019)

46. Engel, R., Bose, R. P. Jagadeesh Chandra: A Case Study on Analyzing Inter-organizational Business Processes from EDI Messages Using Physical Activity Mining. Proceedings of the 47th Hawaii International Conference on System Sciences (HICSS), 3858-3867 (2014)

47. ER, M., Arsad, N., Astuti, H.M., Kusumawardani, R.P., Utami, R.A.: Analysis of production planning in a global manufacturing company with process mining. Journal of Enterprise Information Management 31, 317-337 (2018)

48. ER, M., Astuti, H.M., Wardhani, I.R.K.: Material Movement Analysis for Warehouse Business Process Improvement with Process Mining: A Case Study. In: Asia Pacific Business Process Management, pp. 115-127. Springer (2015)

49. Fleig, C., Augenstein, D., Mädche, A.: Process Mining for Business Process Standardization in ERP Implementation Projects - An SAP S/4 HANA Case Study from Manufacturing. In: Proceedings of the 16th International Conference on Business Process Management (BPM) (2018)

50. Fluxicon BV: Interview with the logistics manager of the year (2018)

51. Ho, G.T.S., Lau, H.C.W.: Development of an OLAP-Fuzzy Based Process Mining System for Quality Improvement. In: Shi, Z., Shimohara, K., Feng, D. (eds.) Intelligent Information Processing III, 228, pp. 243-258. Springer, Boston, MA (2007)

52. Ho, G.T.S., Lau, H.C.W., Lee, C.K.M., Ip, A.W.H., Pun, K.F.: An intelligent production workflow mining system for continual quality enhancement. Int J Adv Manuf Technol 28, 792-809 (2006)

53. Knoll, D., Reinhart, G., Prüglmeier, M.: Enabling value stream mapping for internal logistics using multidimensional process mining. Expert Systems with Applications 124, 130-142 (2019)

54. Koosawad, K., Saguansakdiyotin, N., Palangsantikul, P., Porouhan, P., Premchaiswadi, W.: Improving Sales Process of an Automotive Company with Fuzzy Miner Techniques. Proceedings of the 16th International Conference on ICT and Knowledge Engineering (ICT\&KE), 1-6 (2018)

55. Lee, D., Park, J., Pulshashi, I.R., Bae, H.: Clustering and Operation Analysis for Assembly Blocks Using Process Mining in Shipbuilding Industry. In: Song, M., Wynn, M.T., Liu, J. (eds.) Asia Pacific Business Process Management, 159, pp. 67-80. Springer International Publishing, Cham (2013)

56. Park, J., Lee, D., Bae, H.: Event-log-data-based method for efficiency evaluation of block assembly processes in shipbuilding industry. ICIC Express Letters 5, 157-162 (2014)

57. Meincheim, A., Garcia, C.d.S., Nievola, J.C., Scalabrin, E.E.: Combining Process Mining with Trace Clustering: Manufacturing Shop Floor Process - An Applied Case. Proceedings of the 29th International Conference on Tools with Artificial Intelligence (ICTAI), 498-505 (2017) 
58. Nagy, Z., Werner-Stark, A., Dulai, T.: Using Process Mining in Real-Time to Reduce the Number of Faulty Products. In: Welzer, T., Eder, J., Podgorelec, V., Kamišalić Latifić, A. (eds.) Advances in Databases and Information Systems, 11695, pp. 89-104. Springer International Publishing, Cham (2019)

59. Nagy, Z., Werner-Stark, Á., Dulai, T.: An Industrial Application Using Process Mining to Reduce the Number of Faulty Products. In: Benczúr, A. (ed.) New Trends in Databases and Information Systems, 909, pp. 352-363. Springer International Publishing, Cham (2018)

60. Paszkiewicz, Z.: Process Mining Techniques in Conformance Testing of Inventory Processes: An Industrial Application. In: Abramowicz, W. (ed.) Business Information Systems Workshops, pp. 302-313. Springer, Berlin, Heidelberg (2013)

61. QPR Software Plc: Insight into Vaisala's operations with process mining (2012)

62. QPR Software Plc: From opportunity to delivery, end-to-end process transparency for Ruukki (2013)

63. Rozinat, A., Jong, I., Günther, C., Aalst, W.: Conformance Analysis of ASML's Test Process. Mathematics of Computation - Math. Comput. 459 (2009)

64. Saravanan, M.S., Rama Sree, R.J.: Application of Process Mining in Automobile: A Case Study for MG Motors. International Journal of Advanced Research in Computer Science 1, 685-690 (2011)

65. Ulsan Institute: Samsung Electro-Mechanics (2013)

66. Son, S., Yahya, B., Song, M., Choi, S., Hyeon, J.: Process mining for manufacturing process analysis: a case study. Proceedings of the 2nd Asia Pacific Conference on Business Process Management (2014)

67. Viale, P., Frydman, C., Pinaton, J.: New methodology for modeling large scale manufacturing process: Using process mining methods and experts' knowledge. Proceedings of the 9th International Conference on Computer Systems and Applications (AICCSA), 84-89 (2011)

68. Becker, J., Niehaves, B., Poeppelbuss, J., Simons, A.: Maturity Models in IS Research. Proceedings of the 18th European Conference on Information Systems (ECIS) (2010) 